\title{
Methanol extract of Elaeagnus glabra, a Korean medicinal plant, inhibits HT1080 tumor cell invasion
}

\author{
LI-HUA LI ${ }^{1 *}$, IN KYU BAEK ${ }^{1 *}$, JIN HEE KIM ${ }^{1}, \mathrm{KYUNG}$ HO KANG ${ }^{1}$, YANG SEOK KOH ${ }^{2}$, \\ YOUNG DO JUNG ${ }^{1}, \mathrm{CHOL} \mathrm{KYOON} \mathrm{CHO}^{2}$, SEOK-YONG CHOI ${ }^{1}$ and BOO AHN SHIN ${ }^{1}$ \\ ${ }^{1}$ The Brain Korea 21 Project, Center for Biomedical Human Resources; ${ }^{2}$ Department of Surgery, \\ Chonnam National University Medical School, Gwangju 501-190, Korea
}

Received October 6, 2008; Accepted November 29, 2008

DOI: $10.3892 /$ or_00000257

\begin{abstract}
Elaeagnus glabra (Thunb.), an evergreen shrub with alternate leaves, has been used as a medicinal plant in Korea. Since many plant-derived molecules have inhibitory effects on tumor cell invasion, primarily via suppression of the activity of matrix metalloproteinases (MMPs), we investigated the effect of the methanol extract of E. glabra on tumor cell invasion. The invasiveness of HT1080 human fibrosarcoma cells were reduced in a dose-dependent manner following $24 \mathrm{~h}$ treatment of up to $200 \mu \mathrm{g} / \mathrm{ml}$ of the E. glabra extract, at which concentration no cytotoxicity occurred. Furthermore, gelatinolytic activities, and the protein and mRNA levels of MMP-2 and MMP-9 were also suppressed with increasing concentrations of the extract. Given that MMP-2 and MMP-9 are instrumental in tumor cell invasion, it is very likely that the reduction in tumor cell invasion by $E$. glabra extract is a consequence, at least in part, of suppressed expression of both MMP-2 and MMP-9. Isolation of a molecule(s) responsible for the extract inhibition of tumor cell invasion would pave the way for the development of a new generation of metastasis inhibitors.
\end{abstract}

\section{Introduction}

Matrix metalloproteinases (MMPs) are a family of zincdependent endopeptidases that remodel and degrade the extracellular matrix (ECM). More than 25 MMPs have been identified to date and MMPs are classified based on their substrate specificity and structural similarity (1-3). The ECM has a complex structure that influences the function and

Correspondence to: Dr Boo Ahn Shin or Dr Seok-Yong Choi, Research Institute of Medical Sciences, Chonnam National University Medical School, Gwangju 501-190, Korea

E-mail: bashin@chonnam.ac.kr; zebrafish@chonnam.ac.kr

${ }^{*}$ Contributed equally

Key words: Elaeagnus glabra, matrix metalloproteinase, MMP-2, MMP-9, cancer, metastasis migration process of its resident cells by offering specific contextual information (4). MMP-mediated degradation of ECM is a hallmark in several pathologic conditions such as arthritis, inflammation, cancer, angiogenesis, cardiovascular, pulmonary, ocular, gastrointestinal and oral diseases $(5,6)$.

Invasion and metastasis, both fundamental properties of malignant cancer cells, are the end result of a complex series of steps involving multiple tumor-host interactions $(7,8)$. Cancer cells metastasize through a series of the following sequential steps: escape from the primary tumor, migration and invasion of surrounding tissues, entrance into the vasculature, transport through the circulatory system, extravasation and growth in a secondary organ $(7,9,10)$. Among these steps, cancer cell migration and invasion of surrounding tissues are mediated in part by MMPs, especially MMP-2 and MMP-9 (11-13).

Many plant-derived compounds possess antitumor activity (14-16) and many Korean medicinal plants have been shown to exert an inhibitory effect on MMP-9 $(17,18)$. Elaeagnus glabra (Thunb.) is an evergreen shrub or small tree with alternate leaves, belongs to the Elaeagnaceae family, inhabits East Asia (especially Korea, Japan and China) and is reported to have anti-bacterial, procoagulant, anti-asthmatic and anti-diarrheal effects (19). Other species of the Elaeagnus genus have been documented to possess therapeutic effects as well. For example, E. angustifolia has anti-nociceptive, anti-inflammatory and muscle relaxing activities (20-22) and E. multiflora, anti-oxidant and antiinflammatory activities (23).

In this study, we investigated the inhibitory effect of the methanol extract of the bark derived from E. glabra on tumor invasion using a human fibrosarcoma cell line HT1080.

\section{Materials and methods}

Plant extract. The methanol extract of Elaeagnus glabra bark was purchased from the Plant Extract Bank (Daejeon, South Korea).

Cell culture. A human fibrosarcoma cell line HT1080 was purchased from the American Type Culture Collection (ATCC, USA). The cells were cultured in minimum essential medium (MEM; Gibco, USA) containing penicillin (100 $\mathrm{U} / \mathrm{ml})$, streptomycin $(100 \mu \mathrm{g} / \mathrm{ml})$ and $10 \%$ fetal bovine serum 


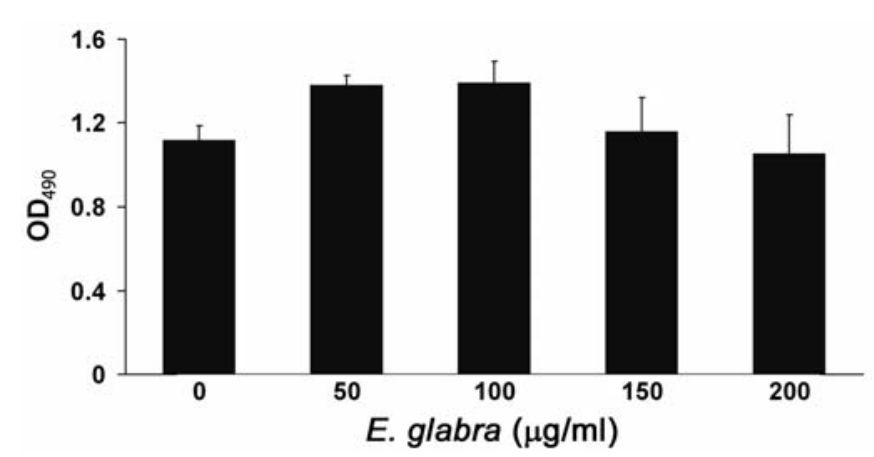

Figure 1. The methanol extract of E. glabra at concentrations up to $200 \mu \mathrm{g} / \mathrm{ml}$ does not exert cytotoxicity on HT1080 cells. HT1080 cells in serum-free MEM were left untreated or treated with the indicated concentration of the E. glabra extract, incubated for $24 \mathrm{~h}$ and subjected to MTT assay for quantifying cell growth. The bar graph shows the absorbance at $490 \mathrm{~nm}$ measured on an ELISA reader $(n=3$ independent experiments; mean \pm standard deviation is shown).

(FBS; Gibco; denoted as complete MEM hereafter) at $37^{\circ} \mathrm{C}$ in $5 \% \mathrm{CO}_{2}$ air. After the cells adhered, the media was replaced with serum-free MEM and the indicated concentration of the extract was added. Conditioned media were collected and the cells were harvested after a 24-h incubation at $37^{\circ} \mathrm{C}$ in $5 \% \mathrm{CO}_{2}$ air.

MTT cell viability assay. HT1080 cells were seeded onto a 96-well culture plate at a density of $4 \times 10^{4}$ cells/well in $200 \mu 1$ of complete MEM and incubated overnight. On the second day of culture, the media was replaced with $200 \mu 1$ of serumfree MEM and treated with the indicated concentration of E. glabra extract $(0-200 \mu \mathrm{g} / \mathrm{ml})$. On the third day, $100 \mu \mathrm{g}$ of 3-(4, 5-dimethylthiazol-2-yl)-2, 5-diphenyltetrazolium bromide (MTT; Sigma, USA) was added to each well and incubated for $4 \mathrm{~h}$. The media was then discarded and $100 \mu \mathrm{l}$ of dimethyl sulfoxide (DMSO; Sigma) was added. Absorbance was measured at $490 \mathrm{~nm}$ on an ELISA reader.

Invasion assay. HT1080 cells $\left(5 \times 10^{4}\right)$ in $250 \mu 1$ of complete MEM were seeded in the upper chamber of a 10-well chemotaxis chamber (Neuro Probe, USA) and serum-free MEM was placed in the lower chamber. A Matrigel-coated membrane was inserted between the two chambers. Following overnight incubation at $37^{\circ} \mathrm{C}$, the media in the upper chamber was replaced with serum-free MEM and treated with the indicated concentration of E. glabra extract. Upon an additional 24-h incubation at $37^{\circ} \mathrm{C}$ in $5 \% \mathrm{CO}_{2}$ air, the membrane was fixed and stained with a Hemacolor rapid staining kit (Merck, Germany) as per manufacturer's instructions.

Gelatin zymography. The quantity of protein in the conditioned media was determined with a BSA protein assay kit (Pierce, USA). Subsequently, the conditioned media was mixed with an equal volume of $2 \mathrm{X}$ sample loading buffer (62.5 mM Tris- $\mathrm{HCl}$ (pH 6.8), 25\% glycerol, 4\% sodium dodecyl sulfate (SDS) and $0.01 \%$ bromophenol blue; BioRad, USA) and loaded onto a $7.5 \%$ acrylamide:bisacrylamide (29:1; Bio-Rad) gel containing $625 \mu \mathrm{g} / \mathrm{ml}$ gelatin (Sigma). Upon electrophoresis at $100 \mathrm{~V}$ for $2 \mathrm{~h}$, the gel was soaked in $1 \mathrm{X}$ zymogram renaturation buffer (Bio-Rad) on a rocker for $1.5 \mathrm{~h}$ at room temperature to remove residual SDS, rinsed in distilled water, incubated at $37^{\circ} \mathrm{C}$ for $18 \mathrm{~h}$ in $1 \mathrm{X}$ zymogram development buffer (Bio-Rad), stained with $0.25 \%(\mathrm{w} / \mathrm{v})$ coomassie brilliant blue R-250 (Bio-Rad) and then destained in destaining buffer (10\% acetic acid and $20 \%$ methanol).

Western blotting. HT1080 cells were treated with the indicated concentration of methanol extract of E. glabra for $24 \mathrm{~h}$ and the conditioned media were harvested. The cells were then scraped into $1 \mathrm{X}$ cell lysis buffer (Cell Signaling, USA) and incubated for $10 \mathrm{~min}$ on ice. The resulting cell lysate was cleared by centrifugation at $6,700 \times \mathrm{g}$ at $4^{\circ} \mathrm{C}$ for $5 \mathrm{~min}$. The supernatant containing cytosolic proteins was collected and the protein concentration of the supernatant and the conditioned media was measured with a BSA protein assay kit. The conditioned media or the cell lysate, with the same amount of protein, was mixed with an equal volume of $2 \mathrm{X}$ sample loading buffer, boiled for $5 \mathrm{~min}$, cooled on ice for $5 \mathrm{~min}$ and then analyzed by $8 \%$ SDS polyacrylamide gel electrophoresis (SDS-PAGE). Subsequently, the separated proteins were transferred to a nitrocellulose membrane (Amersham, USA). The membrane was blocked with 5\% skim milk in $1 \mathrm{X}$ TBST [0.01 $\mathrm{M}$ Tris $(\mathrm{pH} 7.6), 0.1 \mathrm{M} \mathrm{NaCl}$ and $0.1 \%$ Tween-20] for $2 \mathrm{~h}$ at room temperature with shaking and incubated with the indicated primary antibody, followed by HRP-conjugated secondary antibody. The immunoreactive protein bands were visualized with enhanced chemiluminescent reagents (Amersham).

Northern blotting. HT1080 cells treated with the indicated concentration of methanol extract of E. glabra for 24 h were washed with ice-cold $1 \mathrm{X}$ phosphate buffered saline (PBS) twice and the total RNA was extracted with TRIzol Reagent (Invitrogen, USA) as per manufacturer's instructions. The extracted total RNA $(20 \mu \mathrm{g})$ was separated on a $1 \%$ agaroseformaldehyde gel in 1X 4-morpholinepropanesulfonic acid (MOPS) buffer [20 mM MOPS (pH 7.0), 1 mM EDTA (pH 8.0) and $2 \mathrm{mM}$ sodium acetate]. The separated RNA was transferred onto a Hybond-N membrane (Amersham) by capillary transfer in $20 \mathrm{X} \mathrm{SSC}[3 \mathrm{M} \mathrm{NaCl}$ and $0.3 \mathrm{M}$ sodium citrate ( $\mathrm{pH}$ 7.0)] and immobilized by UV cross-linking. The membrane was incubated in Rapid-Hyb buffer (Amersham) harboring human MMP-2 and MMP-9 cDNA probes radiolabeled with $\left[\alpha^{-32} \mathrm{P}\right] \mathrm{dCTP}$ using a random primer method, washed and exposed to X-ray film.

Statistical analysis. Intensity of bands in images was quantitated with the NIH ImageJ software (24). Results are expressed as mean \pm standard deviation. Statistical significance was determined at $\mathrm{p}<0.05$ using Student's t-test.

\section{Results}

E. glabra extract is not toxic to HT1080 cells. HT1080 is a human fibrosarcoma cell line that has been extensively used to study the migration and invasion of tumor cells. Moreover, HT1080 cells express high levels of MMP-2 and MMP-9 (25), which play an important role in tumor cell invasion. 


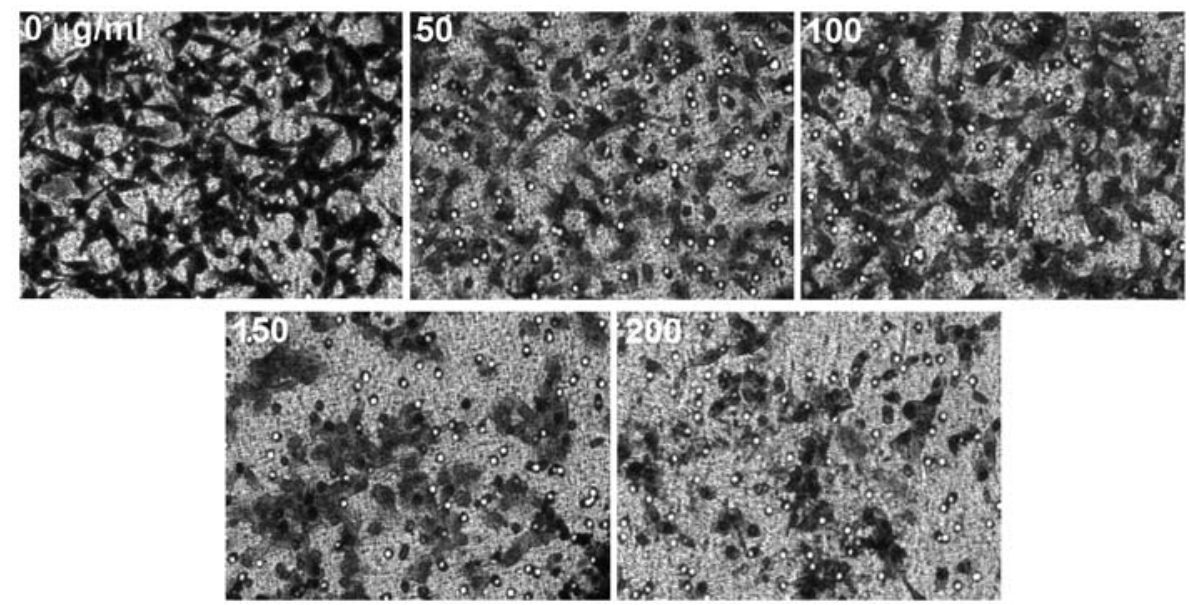

Figure 2. The methanol extract of E. glabra impedes invasiveness of HT1080 cells. A 10-well chemotaxis chamber was used to measure HT1080 cell invasiveness upon treatment with the indicated concentration of the E. glabra extract. A Matrigel-coated membrane inserted between the upper and lower chambers was stained with a Hemacolor rapid staining kit. The stained area represents cells which have migrated from the upper chamber. The number in each panel denotes the concentration of the E. glabra extract added. Each image is representative of 3 independent experiments.

Therefore, we chose HT1080 cells to investigate the effect of E. glabra on tumor cell invasion.

To test if the E. glabra extract is cytotoxic, HT1080 cells were cultured with E. glabra extract $(0-200 \mu \mathrm{g} / \mathrm{ml})$ for $24 \mathrm{~h}$ and then subjected to MTT assay. The methanol extract of E. glabra did not significantly inhibit the growth of HT1080 cells at concentrations ranging between 0 and $200 \mu \mathrm{g} / \mathrm{ml}$ (Fig. 1), suggesting that the E. glabra extract has no significant effect on the HT1080 cell survival. Thus, we performed all subsequent experiments with the extract concentrations ranging between 0 and $200 \mu \mathrm{g} / \mathrm{ml}$.

E. glabra extract inhibits HT1080 cell invasion. Since many natural plant products exhibit an anti-invasiveness effect (26), we questioned whether the E. glabra extract inhibits tumor cell invasion. To this end, we carried out a Matrigel invasion assay with HT1080 cells treated with the E. glabra extract. The extract inhibited the invasive activities of HT1080 cells in a dose-dependent manner (Fig. 2), demonstrating that the E. glabra extract has an anti-invasiveness effect, at least with respect to HT1080 cells.

\section{E. glabra extract inhibits MMP-2 and MMP-9 activities.} Since MMP-2 and MMP-9 play a pivotal role in tumor cell invasiveness, we wished to assess the effect of E. glabra extract on MMP-2 and MMP-9 enzyme activities. For this goal, we performed gelatin zymography with conditioned media harvested from the extract treated HT1080 cells. The gelatinolytic activities of both MMP-2 and MMP-9 were reduced with increasing concentrations of the extract (Fig. 3), suggesting that a decrease in HT1080 cell invasion is a consequence, at least in part, of reduced activities of both MMP-2 and MMP-9.

E. glabra extract reduces MMP-2 and MMP-9 protein levels. MMP enzyme activity is regulated at both transcriptional and post-transcriptional levels (27). To determine whether the reduced MMP-2 and MMP-9 enzyme activities were caused by a decrease in MMP-2 and MMP-9 protein levels, HT1080
A

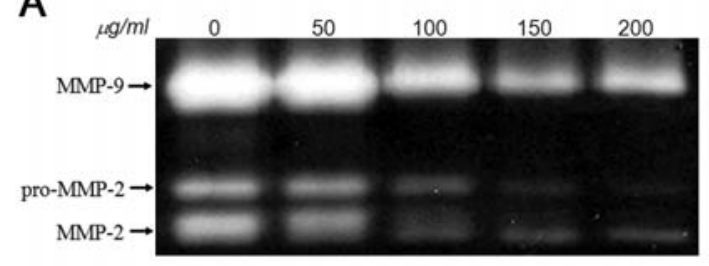

B

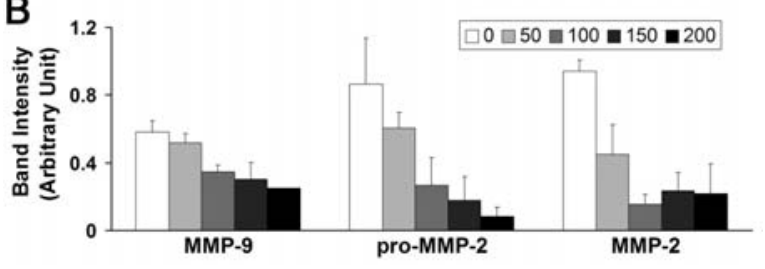

Figure 3. The methanol extract of E. glabra inhibits gelatinolytic activities of MMP-2 and MMP-9. (A) The conditioned media harvested from the HT1080 cells treated for 24 h with the indicated concentration of the E. glabra extract were analyzed by gelatin zymography. The white bands represent MMP-mediated gelatin digestion. The image is representative of three independent experiments. Quantitation of band intensity is shown in B $(\mathrm{n}=3)$. Numbers in the box represent the concentration of the extract in $\mu \mathrm{g} / \mathrm{ml}$ added to the cells. Bars represent the average intensity of each band \pm standard deviation.

cells treated with the E. glabra extract were processed for Western blotting along with their conditioned media. MMP-2 and MMP-9 protein levels were reduced in a dose-dependent manner in both conditioned media (Fig. 4B and D) and cells treated with the extract (Fig. 4A and C), indicating that decreased gelatinolytic activities of MMP-2 and MMP-9 in the extract treated cells ensue from, at least in part, the downregulation of MMP-2 and MMP-9 proteins.

E. glabra extract suppresses MMP-2 and MMP-9 mRNA levels. To examine whether the decreased MMP-2 and MMP-9 protein levels in the HT1080 cells treated with the E. glabra extract result respectively from the reduction in MMP-2 and MMP-9 mRNA levels, we turned to Northern blotting to measure their mRNA levels. Expression of both 
A

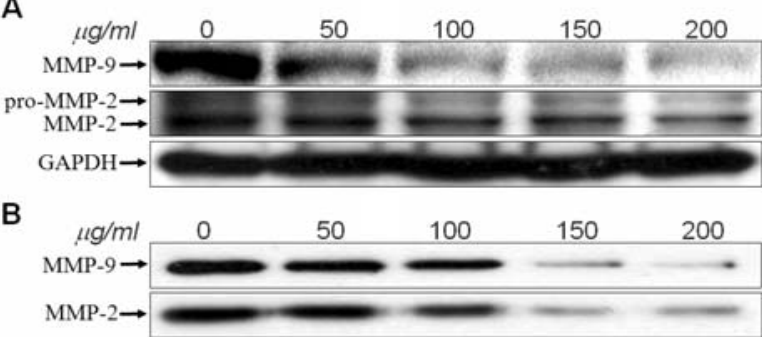

C

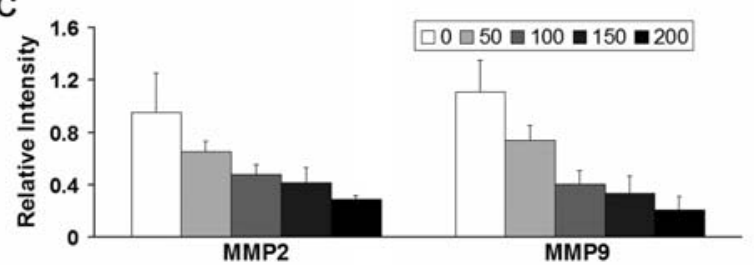

D

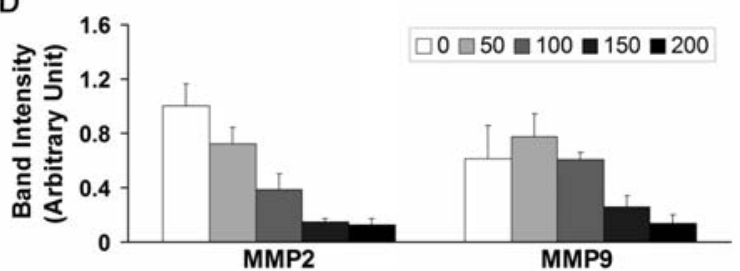

Figure 4. The methanol extract of E. glabra reduces expression of MMP-2 and MMP-9 proteins in HT1080 cells. The cells were treated with the indicated concentration of the E. glabra extract for $24 \mathrm{~h}$. Subsequently, the cells (A and C) and their conditioned media (B and D) were processed for Western blotting. Glyceraldehyde 3-phosphate dehydrogenase (GAPDH) was used as a loading control. Each image is representative of 3 independent experiments. Quantitation of MMP-2 and MMP-9 band intensity in A normalized to that of GAPDH is shown in $C(n=3)$. Quantitation of band intensity in $B$ is shown in $D(n=3)$. Numbers in the box in $C$ and $D$ represent the concentration of the extract in $\mu \mathrm{g} / \mathrm{ml}$ added to the cells. Bars indicate the average intensity of each band \pm standard deviation.

MMP-2 and MMP-9 mRNA decreased in the extract treated cells with increasing concentrations of the extract (Fig. 5), signifying that the decrease in MMP-2 and MMP-9 protein levels in the extract treated cells reflects, at least in part, the reduction in MMP-2 and MMP-9 mRNA levels, respectively.

\section{Discussion}

Herein, we show that the methanol extract of E. glabra suppresses cell invasion, gelatinolytic activities, and protein and mRNA expressions of both MMP-2 and MMP-9 in HT1080 cells. In light of the instrumental role for MMP-2 and MMP-9 in tumor cell invasion, it is very likely that $E$. glabra extract inhibition of MMP-2 and MMP-9 expression leads to a decrease in gelatinolytic activity of MMP-2 and MMP-9, which in turn dampens tumor cell invasion. However, we cannot rule out the following possibilities: i) the E. glabra extract inhibits tumor cell invasion independently of reduction in MMP-2 and MMP-9 activity or expression; ii) the E. glabra extract directly inhibits MMP-2 and MMP-9 proteins independently of a reduction in MMP-2 and MMP-9 expression, leading to suppression of tumor cell invasion; iii) the E. glabra extract promotes activity of MMP inhibitors, e.g., tissue inhibitors of metalloproteinase (TIMP),

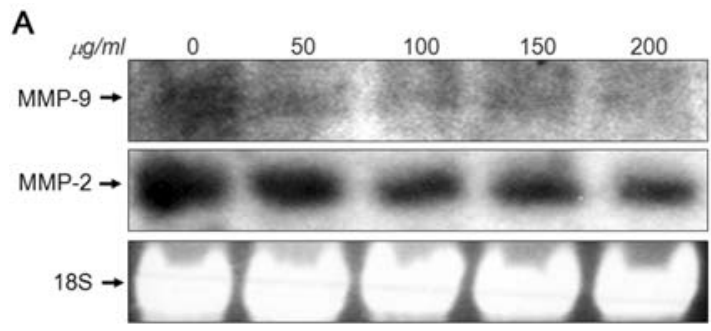

B

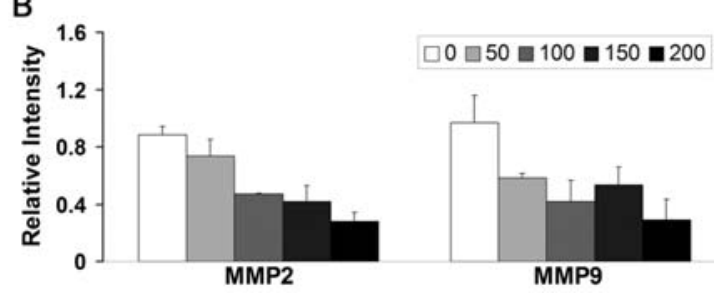

Figure 5. The methanol extract of the E. glabra suppresses expression of MMP-2 and MMP-9 mRNAs in HT1080 cells. (A) The cells were treated with the indicated concentration of E. glabra extract for $24 \mathrm{~h}$ and then processed for Northern blotting. Ribosomal RNA 18S was used as a loading control. Images are representative of 3 independent experiments. Quantitation of band intensity in A normalized to that of ribosomal RNA 18S is shown in $B(n=3)$. Numbers in the box represent the concentration of the extract in $\mu \mathrm{g} / \mathrm{ml}$ added to the cells. Bars denote the normalized average intensity of each band \pm standard deviation.

thereby repressing MMP activity. Further work is required to clarify this issue.

Even though we demonstrate here that the E. glabra extract inhibits HT1080 tumor cell invasion, which molecule(s) in the extract is responsible for the inhibitory effect remains unknown. There have been several studies on plant-derived molecules inhibiting MMP or tumor cell invasion. For instance, polyphenol, epigallocatechin gallate and epicatechin gallate, all isolated from green tea, individually inhibit MMP-2 and MMP-9 (28,29); obovatal isolated from Magnolia obovata, MMP-2 and tumor cell invasion (30); curcumin, isolated from Curcuma longa, MMP-2, MMP-9 and tumor metastasis (31); and quercetin, a flavonol present in many vegetables and fruits including onions and apples, MMP-2 and MMP-9 (32). Therefore, it would be of high interest to explore whether it is one of these molecules, a novel molecule(s), or both that accounts for the inhibitory effect of the E. glabra extract on tumor cell invasion.

Although MMP is a promising target for anticancer therapy, efforts to develop MMP inhibitor with few side effects have been unsuccessful thus far. In this regard, screening natural products, especially plant products, for anti-MMP activity followed by determining which molecule in the product is responsible for the activity would shed light on the development of a new generation of MMP inhibitors.

\section{Acknowledgements}

We thank Cheorl-Ho Kim for critical reading of the manuscript and Eun Young Choi for encouragement. This work was supported by Chonnam National University, 2008 and the Korea Science and Engineering Foundation through the Medical Research Center for Gene Regulation (R13-2002013-06002-0) at Chonnam National University. 


\section{References}

1. Brinckerhoff CE and Matrisian LM: Matrix metalloproteinases: a tail of a frog that became a prince. Nat Rev Mol Cell Biol 3: 207-214, 2002.

2. Egeblad M and Werb Z: New functions for the matrix metalloproteinases in cancer progression. Nat Rev Cancer 2: 161-174, 2002.

3. Visse R and Nagase H: Matrix metalloproteinases and tissue inhibitors of metalloproteinases: structure, function, and biochemistry. Circ Res 92: 827-839, 2003.

4. Daley WP, Peters SB and Larsen M: Extracellular matrix dynamics in development and regenerative medicine. J Cell Sci 121: 255-264, 2008.

5. Konstantinopoulos PA, Karamouzis MV, Papatsoris AG and Papavassiliou AG: Matrix metalloproteinase inhibitors as anticancer agents. Int J Biochem Cell Biol 40: 1156-1168, 2008.

6. Vartak DG and Gemeinhart RA: Matrix metalloproteases: underutilized targets for drug delivery. J Drug Target 15: 1-20, 2007.

7. Mehlen P and Puisieux A: Metastasis: a question of life or death. Nat Rev Cancer 6: 449-458, 2006.

8. Woodhouse EC, Chuaqui RF and Liotta LA: General mechanisms of metastasis. Cancer 80: 1529-1537, 1997.

9. Deryugina EI and Quigley JP: Matrix metalloproteinases and tumor metastasis. Cancer Metastasis Rev 25: 9-34, 2006.

10. Nguyen TH: Mechanisms of metastasis. Clin Dermatol 22: 209-216, 2004

11. Arii S, Mise M, Harada T, et al: Overexpression of matrix metalloproteinase 9 gene in hepatocellular carcinoma with invasive potential. Hepatology 24: 316-322, 1996

12. Giannelli G, Bergamini C, Marinosci F, et al: Clinical role of MMP-2/TIMP-2 imbalance in hepatocellular carcinoma. Int J Cancer 97: 425-431, 2002.

13. Klein G, Vellenga E, Fraaije MW, Kamps WA and de Bont ES: The possible role of matrix metalloproteinase (MMP)-2 and MMP-9 in cancer, e.g. acute leukemia. Crit Rev Oncol Hematol 50: 87-100, 2004.

14. Miller MJ, Bobrowski P, Shukla M, Gupta K and Haqqi TM: Chondroprotective effects of a proanthocyanidin rich Amazonian genonutrient reflects direct inhibition of matrix metalloproteinases and upregulation of IGF-1 production by human chondrocytes. J Inflamm 4: 16, 2007.

15. Sigstedt SC, Hooten CJ, Callewaert MC, et al: Evaluation of aqueous extracts of Taraxacum officinale on growth and invasion of breast and prostate cancer cells. Int J Oncol 32: 1085-1090, 2008.

16. Van Slambrouck S, Daniels AL, Hooten CJ, et al: Effects of crude aqueous medicinal plant extracts on growth and invasion of breast cancer cells. Oncol Rep 17: 1487-1492, 2007.

17. Cha BY, Park CJ, Lee DG, et al: Inhibitory effect of methanol extract of Euonymus alatus on matrix metalloproteinase-9. J Ethnopharmacol 85: 163-167, 2003.
18. Lee KH: Current developments in the discovery and design of new drug candidates from plant natural product leads. J Nat Prod 67: 273-283, 2004.

19. Nishino C, Enoki N, Tawata S, Mori A, Kobayashi K and Fukushima M: Antibacterial activity of flavonoids against staphylococcus epidermidis, a skin bacterium. Agric Biol Chem 51: 139-143, 1987.

20. Ahmadiani A, Hosseiny J, Semnanian S, et al: Antinociceptive and anti-inflammatory effects of Elaeagnus angustifolia fruit extract. J Ethnopharmacol 72: 287-292, 2000.

21. Hosseinzadeh H, Ramezani M and Namjo N: Muscle relaxant activity of Elaeagnus angustifolia L. fruit seeds in mice. J Ethnopharmacol 84: 275-278, 2003.

22. Ramezani M, Hosseinzadeh $\mathrm{H}$ and Daneshmand $\mathrm{N}$ : Antinociceptive effect of Elaeagnus angustifolia fruit seeds in mice. Fitoterapia 72: 255-262, 2001.

23. Lee YS, Chang ZQ, Oh BC, Park SC, Shin SR and Kim NW: Antioxidant activity, anti-inflammatory activity, and whitening effects of extracts of Elaeagnus multiflora Thunb. J Med Food 10: 126-133, 2007

24. Abramoff MD, Magelhaes PJ, Ram SJ: Image processing with image j. Biophotonics International 11: 36-42, 2004

25. Oba K, Konno H, Tanaka T, et al: Prevention of liver metastasis of human colon cancer by selective matrix metalloproteinase inhibitor MMI-166. Cancer Lett 175: 45-51, 2002

26. Bracke ME, Vanhoecke BW, Derycke L, et al: Plant polyphenolics as anti-invasive cancer agents. Anticancer Agents Med Chem 8: 171-185, 2008.

27. Overall CM and Lopez-Otin C: Strategies for MMP inhibition in cancer: innovations for the post-trial era. Nat Rev Cancer 2: $657-672,2002$

28. Adhami VM, Ahmad N and Mukhtar H: Molecular targets for green tea in prostate cancer prevention. J Nutr 133: S2417-S2424, 2003.

29. Demeule M, Brossard M, Page M, Gingras D and Beliveau R: Matrix metalloproteinase inhibition by green tea catechins. Biochim Biophys Acta 1478: 51-60, 2000.

30. Lee SK, Chun HK, Yang JY, Han DC, Son KH and Kwon BM: Inhibitory effect of obovatal on the migration and invasion of HT1080 cells via the inhibition of MMP-2. Bioorg Med Chem 15: 4085-4090, 2007.

31. Shankar S, Ganapathy S, Chen Q and Srivastava RK: Curcumin sensitizes TRAIL-resistant xenografts: molecular mechanisms of apoptosis, metastasis and angiogenesis. Mol Cancer 7: 16, 2008.

32. Vijayababu MR, Arunkumar A, Kanagaraj P, Venkataraman P, Krishnamoorthy G and Arunakaran J: Quercetin downregulates matrix metalloproteinases 2 and 9 proteins expression in prostate cancer cells (PC-3). Mol Cell Biochem 287: 109-116, 2006. 